\title{
Infection control in Finnish acute care hospitals 2008
}

\author{
Tommi Kärki, Petri Ruutu, Outi Lyytikäinen
}

National Institute for Health and Welfare, Helsinki, Finland

doi: 10.3396/ijic.V7i4.030.11

\begin{abstract}
Infection control (IC) in hospitals depends on adequate human resources and organization. The aim of the study was to assess the IC resources and activities in Finnish acute care hospitals. A questionnaire covering information on hospital characteristics, IC staff and surveillance activities in 2008 was mailed to all Finnish acute care hospitals. All $57(100 \%)$ hospitals responded. Of the hospitals, 70\% had infectious disease specialists and $37 \%$ had clinical microbiologists who participated in the IC. Most of the hospitals (88\%) had trained IC nurses. The median number of hospital beds per full-time equivalent ICN was 257 (range, 87-770). The IC staff had limited secretarial and IT-support. Most hospitals (95\%) had IC committees as well as a link nurse system $(96 \%)$, and they all implemented incidence surveillance at least in one specialty. In comparison with the results from our previous study in 2000, the ICN to bed ratio has improved (2000: range 394-953 beds/ ICN). Now that the situation with IC staff seems better, the focus could be shifted to additional training and an evaluation of the curriculum of the ICNs.
\end{abstract}

\section{Key words}

Infection control, resources, organization, activities, surveillance

\section{Introduction}

The healthcare system in Finland (population 5.3 million) is organized into five tertiary care regions with catchment populations ranging from 0.69 million to 1.8 million, and further divided into 20 healthcare districts, which have a consulting role in the infection control (IC) activities in their area.
It is estimated that some 50,000 healthcare-associated infections (HAIs) per year occur in Finnish acute care hospitals, which contribute to the deaths of 1,500 patients annually. These infections also have considerable economic impact; it is estimated that in Finland they cause additional annual costs in the region of EUR 195-492 million. ${ }^{1,2,3,4}$

\section{Corresponding author}

Tommi Kärki

National Institute for Health and Welfare, Helsinki, Finland

Email: tommi.karki@thl.fi 
The control of HAls is important from both a human and economic perspective. Recent studies have shown that at least one fifth of HAls could be prevented with control measures. ${ }^{5}$ In surveillance and control activities, the adequacy of human resources plays a crucial role; IC cannot succeed efficiently without adequate human resources.

In 2001 the Finnish Hospital Infection Program (SIRO) of the National Institute for Health and Welfare (THL) (formerly the National Public Health Institute) conducted a survey on the infection control resources in Finnish acute care hospitals. The 2001 survey identified 41 full- or part-time IC nurses, and the range of hospital beds per an IC nurse was 400-1000. ${ }^{6}$ The aim of the new survey was to estimate the state of human resources and activities in infection control, and the changes that have occurred during the last eight years.

\section{Methods}

In the beginning of 2009 a questionnaire was sent to all Finnish acute care hospitals. Psychiatric and longterm care facilities were excluded from the survey, as well as the region of Åland. The questionnaire was sent to staff in charge of the IC, and healthcare district administration was informed. The survey was conducted with confidentiality and the results were published in a form where single hospitals would not be recognizable.

The questionnaire covered the following aspects:

- Hospital characteristics: hospital type, size and activities; hand rub consumption; number of isolation rooms

- Human resources: medical doctors participating in the IC and their work time spent in IC activities; IC nurses and the distribution of their work time on different IC activities; the training of IC nurses; link-nurse system; infection committee and its activity; technical and secretarial support for IC.

- Surveillance: continuous incidence surveillance on different types of HAls; prevalence surveys; antimicrobial consumption and resistance; staff infections; IT-based register program and alarm system for multidrug-resistant organisms (e.g. meticillin resistant Staphylococcus aureus, MRSA).
The data were analyzed using the SPSS 16 and STATA 9.0 programs. Means, medians and ranges were calculated by hospitals and healthcare districts. In the tables the results are shown by the tertiary care districts.

\section{Results}

All hospitals (57) responded to the questionnaire: 5 tertiary (16 separate units), 15 secondary and 26 other acute care centres. The median number of beds per hospital was 163 (range by hospital, 16-1076) (Table I). Of the hospitals, $51 \%$ had ICUs, and in $84 \%$ surgical procedures were performed.

Of the hospitals, $70 \%$ had an infectious disease specialist and $37 \%$ had a clinical microbiologist participating in the IC activities (Table I). All of the tertiary and secondary care hospitals had at least one IC physician. Altogether infectious disease specialists used $20 \%$ of their work time in IC (median, 20\%; range, 2-66\%), clinical microbiologists less (median, $5 \%$; range $1-30 \%$ ). In five out of 20 different healthcare districts one of the physicians was working on project funding.

Of the hospitals, $88 \%$ had either full time or part time IC nurses, whose total input in IC varied from three hours per week to full time equivalent (FTEQ). Most of them $(85 \%)$ had received special training in IC. Others had acquired either special training in infectious diseases or had had some other relevant training. One out of five $(21 \%)$ had a special certification of expertise in IC provided by The Finnish Society for Hospital Infection Control. IC nurses used from $25 \%$ to $100 \%$ of their work time in the IC activities of their own hospital, the median being $70 \%$, and the remaining proportion was spent on external IC activities and other tasks. The median number of beds per an ICN in all hospitals was 253 (range by hospital, 87-770) (Table I). In 15 out of 20 healthcare districts, 23 out of a total of 86 $(27 \%)$ IC nurses were working on project funding. In addition, some hospitals had nurses who participated in IC alongside their own work.

Of the hospitals, $16 \%$ had IT-staff and 30\% secretarial support services participating in IC. In these hospitals the mean work time of technical staff spent in IC was 3 weeks per year and for secretarial staff 29 weeks per year. 
Table I. Tertiary care region characteristics and infection control (IC) personnel

Tertiary care regions

\begin{tabular}{lrrrrrr}
\hline & Turku & Tampere & Helsinki & Kuopio & \multicolumn{2}{c}{ Oulu Whole country } \\
\hline Population (31.12.2008) & 692202 & 1225128 & 1800777 & 849739 & 731012 & 5298858 \\
\hline Hospitals & 8 & 9 & 23 & 9 & 8 & 57 \\
\hline All beds & 1894 & 3233 & 4320 & 2468 & 1819 & 13734 \\
\hline Intensive care beds & 47 & 78 & 145 & 41 & 57 & 368 \\
\hline All patient-days & 495627 & 986252 & 1272725 & 680906 & 555998 & 3991508 \\
\hline Intensive care patient-days & 12037 & 19905 & 30894 & 10611 & 15159 & 88606 \\
\hline Surgical procedures & 60546 & $60665^{1}$ & 113458 & 67868 & 61808 & 364345 \\
\hline
\end{tabular}

IC personnel (number)

\begin{tabular}{lrrrrrr}
\hline Infectious disease specialists & 5 & 10 & 19 & 8 & 4 & 46 \\
\hline Clinical microbiologists & 2 & 4 & 3 & 5 & 3 & 17 \\
\hline IC nurses & 12 & 17 & 26 & 14 & 17 & 86 \\
\hline Beds/ IC nurse average & 369 & 365 & 227 & 334 & 228 & 285 \\
(median) & $(257)$ & $(388)$ & $(199)$ & $(296)$ & $(175)$ & $(253)$ \\
\hline
\end{tabular}

'Information on surgical procedures partly missing.

Almost all hospitals had an IC committee, which meet on average 3 times per year (range, 1-9) (Figure 1). There was at least one IC committee in every healthcare district. Likewise, almost all hospitals had a link nurse system covering all wards. Approximately $80 \%$ of hospitals had an IT-based register program, as well as an alarm system for identifying carriers of multidrug-resistant organisms (e.g. MRSA).

Continuous incidence surveillance on surgical site infections was conducted in $92 \%$ of the hospitals providing surgical services. Surveillance on ICU infections was implemented in $90 \%$ of the hospitals with ICUs. Surveillance on antimicrobial consumption and resistance, Clostridium difficile and MRSA infections were conducted in approximately $70 \%$ of all the hospitals. Since the national prevalence survey in 2005, in which all of the tertiary and secondary care hospitals participated, a new prevalence survey had been performed in $66 \%$ of the hospitals. Surveillance on staff infections was implemented in $16 \%$ of the hospitals. Forty-four per cent of the hospitals participated in the national SIRO hospital infection program (Figure 1).

Hospital-wide median of hand rub consumption was 46.9 litres per 1000 patient-days (range, 21.6-98.1 litres), in the ICUs the corresponding figure was 119.5 litres (range, 37.6-362.4 litres) (Figure 2).

In the whole country, there were 219 isolation rooms with negative air pressure, an anteroom and separate toilet/shower, 32 of which were located in the ICUs (Table II).

\section{Discussion}

This second survey on IC resources in Finland, in which all Finnish acute care hospitals participated, demonstrated an overall improvement in IC resources since 2001, but showed that the resources are unevenly distributed. In spite of the absence of formal requirements for IC programmes, practically all Finnish 
Table II. Isolation rooms in hospital wards and intensive care units (ICU) (ICU isolation rooms in brackets)

Tertiary care regions

\begin{tabular}{lcccccr}
\hline & Turku & Tampere & Helsinki & Kuopio & Oulu & Whole country \\
\hline $\begin{array}{l}\text { Isolation room with an anteroom, } \\
\text { negative air pressure and separate } \\
\text { toilet/shower }\end{array}$ & $60(6)$ & $30(2)$ & $87(13)$ & $32(6)$ & $10(5)$ & $219(32)$ \\
\hline $\begin{array}{l}\text { Isolation room with an anteroom } \\
\text { and separate toilet/shower }\end{array}$ & 66 & $165(3)$ & $193(6)$ & $121(2)$ & $81(1)$ & $626(12)$ \\
\hline $\begin{array}{l}\text { Isolation room with separate toilet/ } \\
\text { shower }\end{array}$ & 40 & $117(3)$ & $104(2)$ & $58(1)$ & 38 & $357(6)$ \\
\hline
\end{tabular}

acute care hospitals carry out some IC activities and have multidisciplinary IC committees as well as link-nurse systems. As in other European countries, IC expertise in Finland is mainly concentrated in larger tertiary and secondary hospitals, which offer intensive and multiple speciality services. However, in recent years the administrative changes have partly blurred the distinction between hospital types, and therefore divisions in this study were based on larger geographical regions and not on hospital types.
In Europe a similar study was performed in 2001 by Antibiotic Resistance, Prevention And Control (ARPAC). ${ }^{7}$ Some national surveys have also been published recently, for example in Spain, Canada and the United States. ${ }^{8,9,10}$ Making comparisons is in part straightforward, but naturally there are certain national differences with IC programmes and health care organizations that can affect results.

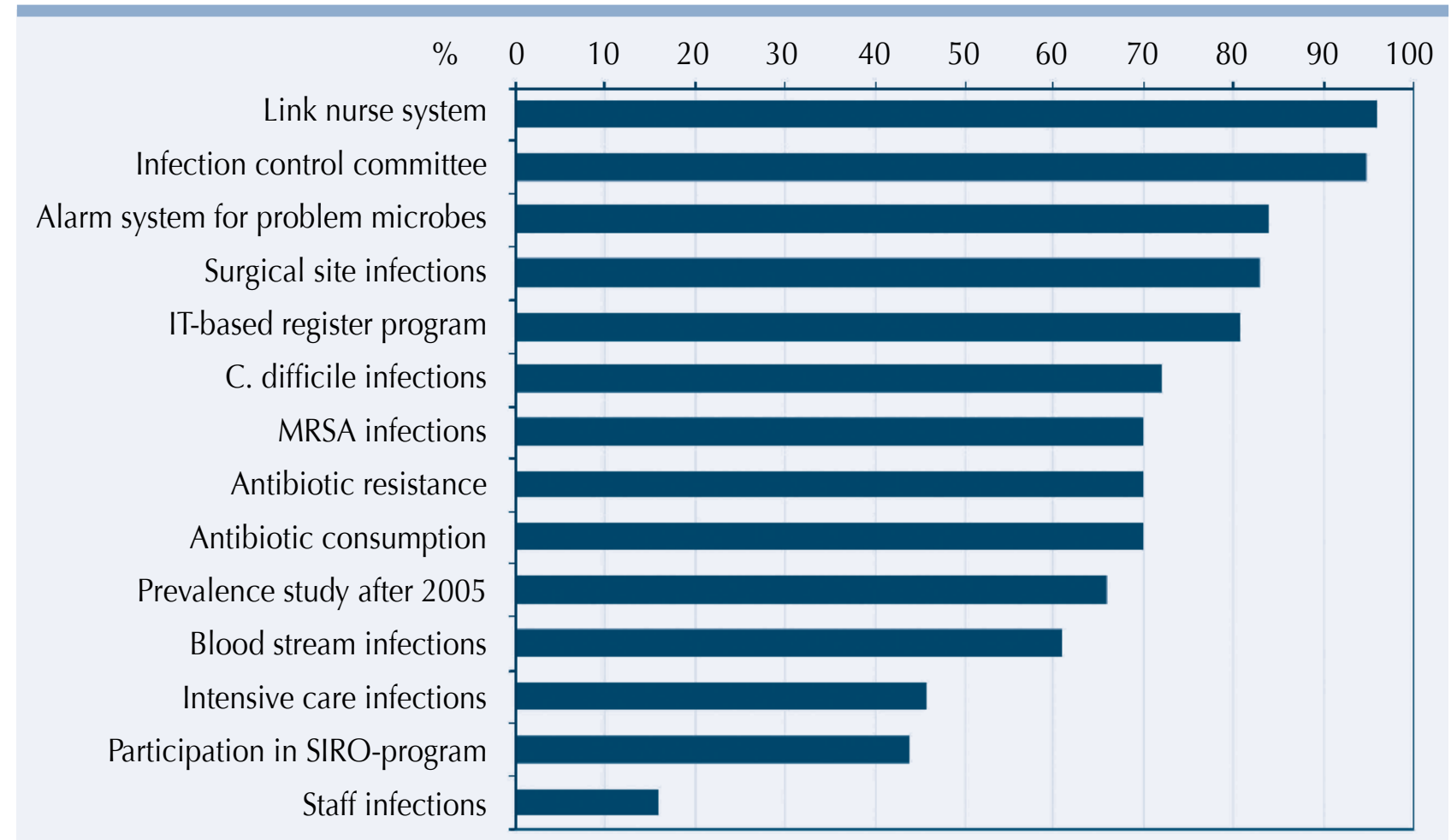

Figure I: Surveillance activities in all hospitals 
In 2008, almost $90 \%$ of the Finnish hospitals had an IC nurse, with specific training from universities of applied sciences. However, the ratio of nurses to beds varied considerably (IC nurse/87-770 beds). On average, the SENIC (Study on the Efficacy of Nosocomial Infection Control) recommendations dating from the 1980 s are being met. ${ }^{11}$ In some hospital districts, the more recent Dutch and Canadian criterions are being met (IC nurse/167-178 beds). ${ }^{12,13}$ In estimating the number of hospital beds per IC nurse, only the work time dedicated to their own hospital was considered, knowing that their work may include a variable amount of IC consultation and training for other healthcare facilities in the area. This approach raises the nationwide mean from 159 beds/ IC nurse to 285, making comparison with the Canadian criterion possible. The nurses doing IC work alongside their own work were excluded, because there was no adequate information available on their training.

In comparison to our previous study from 2001, IC staffing has improved. In 2001, there were 400-1000 beds per IC nurse, and only $60 \%$ (36 out of 62 ) of the hospitals had full- or part-time IC nurses. At that time the Finnish situation was comparable to the results from the European ARPAC study in 2001, in which approximately $80 \%$ of European hospitals had IC nurses and the median number of beds per ICN was 429 ( 2.33 ICNs/1000 beds). In addition to the quantity of IC nurses, it is important to assess their training and the tasks they are responsible for in practice. Most of the IC nurses had completed the special training in IC, which gives basic competence in working in the field.

Over $20 \%$ of all the hospitals had no IC physician or an infectious disease specialist or clinical microbiologist participating in IC activities. These hospitals were all other acute care hospitals. There were also difficulties in defining what exactly was meant by participation in IC activities, which complicates comparisons between hospitals and regions. At a future time, populationbased comparisons of physicians might be easier and more relevant. In 2001, the IC physicians devoted $32 \%$ of their work time to IC activities, but in 2008 this figure was even lower (20\%). Other activities, such as clinical work, limit considerably the amount of work time IC physicians can use on IC. This is understandable, but surely is not an ideal situation.
Only $30 \%$ of the hospitals had secretarial and $16 \%$ had IT support. The situation with the assisting staff was the same in 2001. In the absence of secretarial support, these tasks usually are taken up by ICNs, reducing their work time used on essential IC activities.

Practically all of the Finnish hospitals had an infection control committee (ICC) as well as a link nurse system. In the future, the deployment of link-nurse systems in long-term care facilities should also be assessed. In the ARPAC study 2001, 90\% of European hospitals had an ICC, but a link-nurse system was then deployed only in $46 \%$ of the hospitals. ${ }^{7}$

Surveillance or reporting of HAls is not mandatory in Finland. The Finnish Hospital Infection Program (SIRO) was launched in 1997, and it provides a sentinel network for incidence surveillance of surgical site, nosocomial bloodstream and Clostridium difficile infections. Almost half of the Finnish acute care hospitals participated in the program in 2008 and 30 of them participated in the national prevalence survey in 2005. Most of the hospitals not participating in the national program had their own surveillance systems (Figure 1). All of the hospitals ran incidence surveillance at least in one specialty, most often it was implemented for surgical site infections.

The consumption of alcohol hand rub both in whole hospital and ICUs has clearly increased since the time of our previous study, suggesting that the rigorous work towards improvement of hand hygiene has had an impact. The Finnish ICU consumption in 2008 is almost twice as high as in Germany in 2007. ${ }^{14}$ In Finland, the consumption in the ICUs has grown from 33.5 litres/1000 patient-days in 2000 - 2002 to 119.5 litres in 2008. ${ }^{15}$ However, the increase in consumption does not guarantee efficient hand disinfection, even though it implies that some improvement has been made. $^{15,16}$ In the future, hand rub consumption could be reported by specialty, and it would also be important to conduct direct surveys to evaluate possible deficiencies or errors in the use of hand rub, employing the Guidelines on Hand Hygiene in Health Care by WHO (http://whqlibdoc.who.int/ publications/2009/9789241597906_eng.pdf. 2009). 


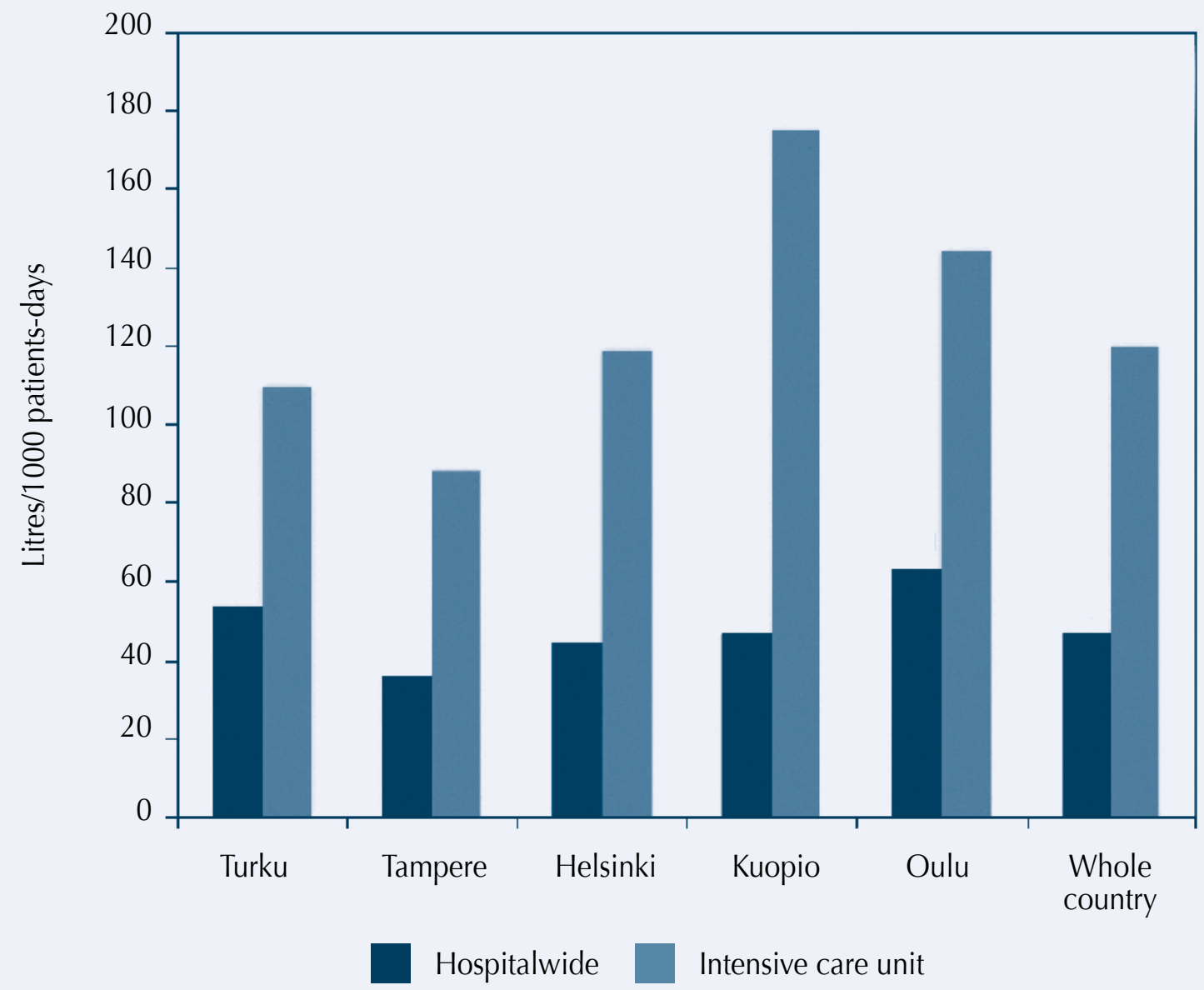

Figure 2: Alcohol hand rub consumption (median)

IC resources in Finland have improved during the last decade. While the situation with IC staff seems better, it is unclear what would be the sufficient minimum amount of human resources in IC. One aim of this survey is to help fill the gaps in some regions and also evaluate the sufficiency of staffing. In the future, partly in line with the French model implemented recently, this survey will serve as a basis for designing webbased repeated surveys for organisational resources and process indicators for $\mathrm{IC}^{17}$

\section{References}

1. Kanerva M, Ollgren J, Virtanen MJ, Lyytikäinen O, sekä kansalliseen sairaalainfektioiden prevalenssitutkimukseen osallistuneet sairaalat. Sairaalainfektiot aiheuttavat huomattavan tautitaakan. Suom Lääkäril 2008; 63: 16971702.

2. Perenkevich EN, Stone PW, Wright SW, Carmeli Y, Fisman DN, Cosgrove SE. Raising standards while watching the bottom line: making a business case for infection control. Infect Control Hosp Epidemiol 2007; 28: 1121-1133. http://dx.doi. org/10.1086/521852

3. Roberts RR, Scott RD II, Cordell R, et al. The use of economic modeling to determine the hospital costs associated with nosocomial infections. Clin Infect Dis 2003; 36: 1424-1432. http://dx.doi.org/10.1086/375061

4. Plowman R, Graves N, Griffin MAS, et al. The rate and cost of hospital-acquired infections occurring in patients admitted to selected specialties of a district general hospital in England and the national burden imposed. I Hosp Infect 2001; 47: 198-209. http://dx.doi.org/10.1053/jhin.2000.0881

5. Lyytikäinen $\mathrm{O}$, Kanerva $M$, Agthe $\mathrm{N}$, Möttönen $\mathrm{T}$. Sairaalainfektioiden esiintyvyys Suomessa 2005. Suom Lääkäril 2005; 60: 3119-3123.

6. Lyytikäinen O, Jalkanen M, Ratia M, et al. Sairaalainfektioiden torjunta Suomen sairaaloissa. Suom Lääkäril 2003; 58: 26232626.

7. Struelens MJ, Wagner D, Bruce J, et al. Status of infection control policies and organisation in European hospitals, 2001: the ARPAC study. Clin Microbiol Infect 2006; 12: 729-737.

8. Sánchez-Payá J, Bischofberger C, Lizan M, et al. Nosocomial infection surveillance and control: current situation in Spanish hospitals. J Hosp Infect 2009; 72: 50-56. http://dx.doi. org/10.1016/j.jhin.2009.01.013

9. Zoutman DE, Ford BD. A comparison of infection control program resources, activities, and antibiotic resistant organism rates in Canadian acute care hospitals in 1999 and 2005: Pre- and post-severe acute respiratory syndrome. Am J Infect Control 2008; 36: 711-717. http://dx.doi.org/10.1016/j. ajic.2008.02.008

10. Herwaldt LA, Appelgate D, Kuntz J, Chen Y, Pottinger JM. Infection control resources in lowa. Am J Infect Control 2007; 35: 662-665. http://dx.doi.org/10.1016/j.ajic.2007.01.014 
11. Haley RW, Culver DH, White JW, et al. The efficacy of infection surveillance and control programs in preventing nosocomial infections in us hospitals. Am J Epidemiol 1985; 121: 182-205.

12. Health Canada. Development of a resource model for infection prevention and control programs in acute, long term, and home care settings: Conference proceedings of the infection prevention and control alliance. Am J Infect Control 2004; 32: 2-6. http://dx.doi.org/10.1016/j.ajic.2003.10.002

13. van den Broek PJ, Kluytmans JAJW, Ummels LC, Voss A, Vandenbroucke-Grauls CMJE. How many infection control staff do we need in hospitals? J Hosp Infect 2007; 65: 108111. http://dx.doi.org/10.1016/j.jhin.2006.10.003
14. Reichardt C, Mönch N, Hansen S, Geffers C, Gastmeier P. Deutschlandweite Referenzdaten des Verbrauchs an Händedesinfektionsmittel. Hygiene \& Medizin 2009; 34: 8-11.

15. Agthe N, Routamaa $M$, Terho $K$ et al. Voiko käsihygieniatuotteiden kulutuksesta päätellä käsihygienian tasoa? Suomen sairaalahygienialehti 2004; 22: 274-282.

16. Heyneman B, Lenez A, Jannes H, Sax H, Pittet D, Gordts B. P10.06 Is Consumption of Hydro-Alcoholic Handrub Solution (HAHS) a Valid Indicator for Compliance with Hand Hygiene? J Hosp Infect 2006; 64: S52-S53. http://dx.doi.org/10.1016/ S0195-6701(06)60172-2

17. Parneix P, Salomon V, Garnier P, Drouvot V, Tran B. Les indicateurs du tableau de bord des infections nosocomiales. Bulletin épidémiologique hebdomadaire 2007; 12-13: 102 104. 